\title{
Terra MODIS: 20 years of on-orbit calibration and Performance (Erratum)
}

\author{
Xiaoxiong Xiong, ${ }^{a}$ Emily Aldoretta, ${ }^{b}$ Amit Angal, ${ }^{b}$ Tiejun Chang, \\ Xu Geng, ${ }^{\text {b }}$ Daniel Link, ${ }^{b}$ Vincent Salomonson, ${ }^{c}$ Kevin Twedt, ${ }^{b}$ and \\ Aisheng $\mathbf{W u}^{\mathrm{b}}$ \\ ${ }^{a}$ NASA Goddard Space Flight Center, Sciences and Exploration Directorate, \\ Greenbelt, Maryland, United States \\ ${ }^{\mathrm{b}}$ Science Systems and Applications Inc., Lanham, Maryland, United States \\ ${ }^{\mathrm{c}}$ University of Utah, Salt Lake City, Utah, United States
}

[DOI: $10.1117 / 1 . J R S .14 .049902]$

This article [J. of Applied Remote Sensing, 14(3), 037501 (8 August 2020) https://doi.org/10 $.1117 / 1 . J R S .14 .037501]$ contained an error in Figure 9 when it was originally published. In the figure, the prelaunch BBR values were erroneously plotted instead of the first year values.

The incorrect figure appeared as:
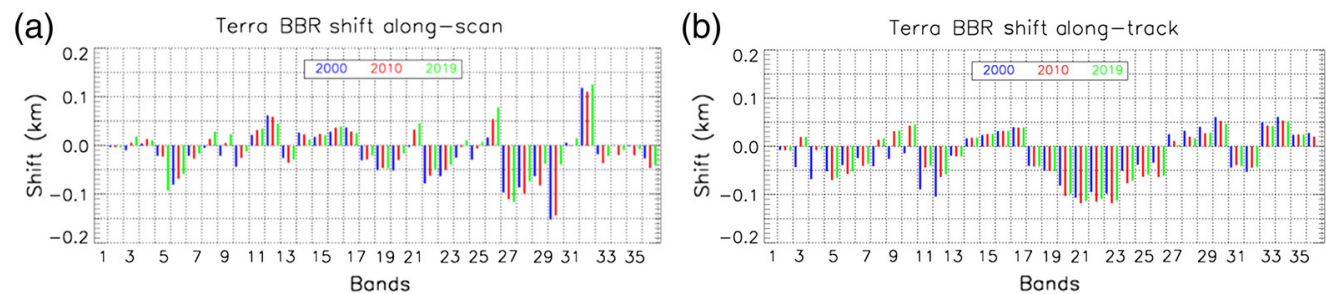

Fig. 9 Terra MODIS BBR in both the (a) along-scan direction and (b) along-track direction for selected years throughout the mission.

The corrected figure is below:
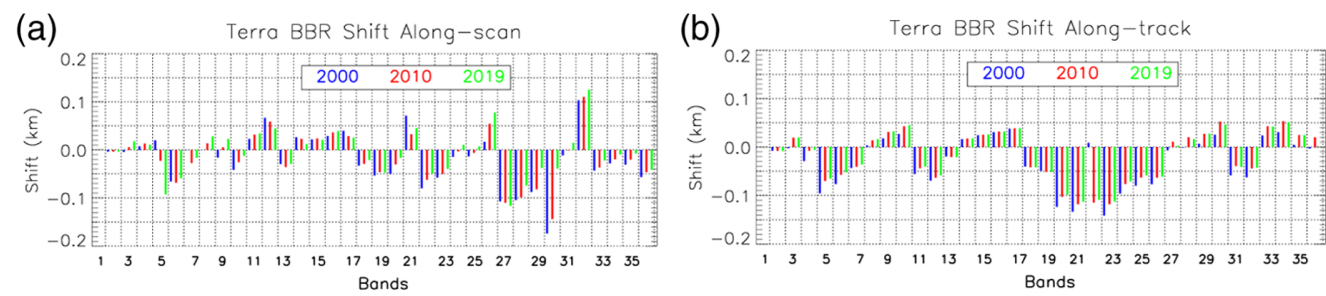

Fig. 9 Terra MODIS BBR in both the (a) along-scan direction and (b) along-track direction for selected years throughout the mission.

All versions of the article were corrected on 21 October 2020. 